\section{Pneumothorax management: time to improve the evidence base}

\author{
Nick A Maskell
}

\section{BACKGROUND}

Pneumothorax remains a common reason for medical admission to hospital with a UK annual incidence of 16.7 cases per 100000 for men and 5.8 cases per 100000 for women. ${ }^{1}$ This equates to around 8000 admissions a year for pneumothorax accounting for 50000 bed days given an average length of stay of just under 1 week. ${ }^{2}$ Despite its frequency and the existence of established guidelines, ${ }^{3}{ }^{4}$ there is still wide variation in pneumothorax management, which is likely to be driven by the paucity of good quality evidence in this field.

Pneumothorax has traditionally been divided into primary spontaneous pneumothorax (PSP), with no known underlying lung disease and secondary spontaneous pneumothorax (SSP), with existing lung disease. This is likely to be too simplistic an approach. Smoking cessation has been shown to significantly reduce the risk of recurrence in PSP and this together with the presence of decreased lung density/ early emphysematous change seen on CT imaging in the lung apexes of current smokers presenting with PSP suggests many cases of PSP having underlying lung abnormalities. $^{5} 6$ As current guidelines triage treatment according to whether they are primary or secondary pneumothorax, a better definition may lead to better algorithms and patient treatments. ${ }^{3}$

So why is the existing evidence so poor? Perhaps because it is so difficult to recruit to good quality randomised controlled trials (RCTs) in this area. The reasons for this include the timing of their presentation, which will often be outside of normal working hours. Added to which, they will often be cared for initially by one specialty (emergency physicians) before being handed over for further management by respiratory or general physicians. By the time they reach a hospital ward, it is often too late to offer them entry into a randomised clinical trial. It is therefore vital that we work together across specialties if we want to improve the evidence base in pneumothorax management.

Correspondence to Professor Nick A Maskell, North Bristol Lung Centre, Southmead Hospital, Bristol University, Bristol BS10 5NB, UK; nick.maskell@bristol. ac.uk
Reassuringly, this is starting to happen with two multicentre RCTs that are currently recruiting. The first is a multicentre Australasian RCT looking at the role for conservative management at first presentation for PSP versus standard care. Patients are being randomly assigning to either observation or standard care with needle aspiration and chest drain insertion. The results of this exciting trial are expected shortly and could lead to significant changes to future patient care.

The second involves the use of Heimlich valves, which is being studied in an RCT recruiting from 20 sites in the UK. The study design requires close collaboration between the respiratory and emergency care teams. It randomises patients with a PSP to standard care following the BTS guidelines and a Heimlich valve insertion with early discharge (RAMPP Trial, www.isrctn.com, ISRCTN79151659). A recent systematic review of 18 studies of ambulatory management reported an overall success rate using only Heimlich valves and outpatient management in $78 \%$ of cases. ${ }^{8}$

Another area attracting a lot of attention is the use of digit air leak devices. These devices which measure the volume of air leak through the chest tube in patients with chest drains in situ and have been used for some time now in postoperative patients who had undergone thoracic surgery. ${ }^{9}$ These commercially available systems are capable of providing regulated suction and validated measurements of air leak. In a series of 142 patients who had undergone thoracic surgery postoperative air leak of $>180 \mathrm{~mL} / \mathrm{min}$ on day 2 after surgery was predictive of a $>5$ day prolonged air leak. ${ }^{9}$ Currently, there is lack of good quality data of their use in PSP/SSP but it has the potential to possibly assist the physician in deciding which patients are likely to require surgery and allow early referral.

Despite these advances, we still do not know the answer to many crucial questions that would allow us to deliver a step change in pneumothorax management. These questions include:

1. What is the true life-time risk of a recurrence after the first episode of PSP?
2. Which patients are at high risk of recurrence and therefore might benefit from definitive management after the first episode?

3. What is the best chemical pleurodesis agent and method of delivery to employ in cases of recurrent pneumothorax?

In Thorax, Halifax RJ, et $a l^{10}$ try to answer one of these questions. They undertook a systematic review of the effectiveness of chemical pleurodesis in spontaneous pneumothorax recurrence prevention. Of the 50 full papers included, there were a total of 9 RCTs, 10 prospective case series and 31 retrospective case series. Given the considerable heterogeneity in study design, pleurodesis agents, control groups and primary outcomes across these studies, it was not possible for them to undertake a formal meta-analysis in their review. Firm recommendations were not possible but could be summarised as follows; For patients fit enough for video-assisted thoracic surgery (VATS) recurrence rates and complications were very low across all studies. Many of these patients had a mixture of mechanical abrasion, bullectomy and pleurectomy. Talc poudrage administration during VATS from eight studies, including over 2300 patients, had a recurrence rate of between $0.0 \%$ and $2.9 \%$. These data together with the recently published Italian series of PSP patients undergoing talc poudrage at the time of surgery ${ }^{11}$ suggest that VATS is highly effective at preventing recurrence and is well tolerated and should be the treatment of choice in cases of recurrence or prolonged air leak. What is less certain is whether this should be performed using talc poudrage or pleurectomy/abrasion and this should be the focus of a future RCT.

For those not fit enough for surgery (largely a population of patients with SSP) and no ongoing air leak, talc slurry or tetracycline appear reasonable options.

Finally, there was some evidence of an effect of autologous blood patch pleurodesis for non-operable patients with a persistent air leak. Its use led to low recurrence rates of between $15 \%$ and $18 \%$ in 270 patients over five studies. An RCT assessing the short-term efficacy of autologous blood patch pleurodesis at varying doses found that administration of 1 or $2 \mathrm{~mL} / \mathrm{kg}$ was more successful at ceasing air leak by 13 day ( $82 \%$ success) than $0.5 \mathrm{~mL} / \mathrm{kg}$ or saline $(27 \%$ or $9 \%$, respectively). However, there is a lack of any study in this area which had drainage alone as the comparator arm. Further studies are therefore required before any firm recommendations can be made. 


\section{Editorial}

Reassuringly, a recently published Cochrane review on malignant pleural effusions also concluded that talc was likely to be the best pleurodesis agent in patients with malignancy. ${ }^{12} 13$ Although it is clearly a very different disease, it is the same 'space' and given with the same ultimate intention.

In conclusion, we are making steady progress in obtaining high-quality pneumothorax data, which will help inform future iterations of national guidelines. Researchers are now starting to cross over specialty lines and by combining, their research efforts are starting to collect robust prospective data which can only be of benefit to future patients.

Competing interests None declared.

Provenance and peer review Commissioned; internally peer reviewed.

(C) Article author(s) (or their employer(s) unless otherwise stated in the text of the article) 2017. All rights reserved. No commercial use is permitted unless otherwise expressly granted.
5 Bintcliffe OJ, Edey AJ, Armstrong L, et al. Lung parenchymal assessment in primary and secondary pneumothorax. Ann Am Thorac Soc 2016;13:350-5.

6 Bintcliffe OJ, Hallifax RJ, Edey A, et al. Spontaneous pneumothorax: time to rethink management? Lancet Respir Med 2015;3:578-88.

To cite Maskell NA. Thorax 2017;72:1065-1066.

Published Online First 25 September 2017

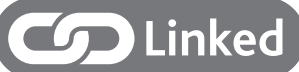

http://dx.doi.org/10.1136/thoraxjnl-2015-207967

Thorax 2017;72:1065-1066.

doi:10.1136/thoraxjnl-2017-211007

\section{REFERENCES}

1 Gupta D, Hansell A, Nichols T, et al. Epidemiology of pneumothorax in England. Thorax 2000;55:666-71.

2 NHS. Data from Health \& Social Care Information Centre. http://www.hscic.gov.uk.

3 MacDuff A, Arnold A, Harvey J, et al. Management of spontaneous pneumothorax: British Thoracic Society Pleural Disease Guideline 2010. Thorax 2010;65:ii18-31.

4 Tschopp JM, Bintcliffe 0, Astoul P, et al. ERS task force statement: diagnosis and treatment of primary spontaneous pneumothorax. Eur Respir $J$ 2015;46:321-35.
7 Brown SG, Ball EL, Perrin K, et al. Study protocol for a randomised controlled trial of invasive versus pneumothorax. BMJ Open 2016;6:e011826.

8 Brims FJ, Maskell NA. Ambulatory treatment in the management of pneumothorax: a systematic review of the literature. Thorax 2013;68:664-9.

9 Billé A, Borasio P, Gisabella M, et al. Air leaks following pulmonary resection for malignancy: risk factors, qualitative and quantitative analysis. Interact Cardiovasc Thorac Surg 2011;13:11-15.

10 Hallifax RJ, Yousuf A, Jones HE, et al. Effectiveness of chemical pleurodesis in spontaneous pneumothorax recurrence prevention: a systematic review. Thorax 2017;72:1121-31.

11 Cardillo G, Bintcliffe OJ, Carleo F, et al. Primary spontaneous pneumothorax: a cohort study of VATS with talc poudrage. Thorax 2016;71:847-53.

12 Clive AO, Bhatnagar R, Preston NJ, et al. Cochrane corner: interventions for the management of malignant pleural effusions. Thorax 2016;71:964-6.

13 Clive $\mathrm{AO}$, Jones $\mathrm{HE}$, Bhatnagar $\mathrm{R}$, et al. Interventions for the management of malignant pleural effusions: a network meta-analysis. Cochrane Database Syst Rev 2016;5:CD010529. conservative management of primary spontaneous 